Research Article

\title{
Deformation Mechanism and Control Technology of the Surrounding Rock of the Floor Roadway under the Influence of Mining
}

\author{
Qingchong Zhao $(\mathbb{D}$, Baojie Fu $\mathbb{D}$, and Jiadi Yin \\ Department of Energy and Security, Anhui University of Science and Technology, Huainan, Anhui 232001, China \\ Correspondence should be addressed to Qingchong Zhao; 1142231702@qq.com
}

Received 20 October 2020; Revised 4 December 2020; Accepted 15 December 2020; Published 29 December 2020

Academic Editor: Zhijie Wen

Copyright (c) 2020 Qingchong Zhao et al. This is an open access article distributed under the Creative Commons Attribution License, which permits unrestricted use, distribution, and reproduction in any medium, provided the original work is properly cited.

\begin{abstract}
Deformation and failure mechanism of the surrounding rock of the floor roadway under the influence of working face mining is complicated, and roadway control is difficult. The floor roadway of the 11123 working face in Pan'er Mine is taken as the research object of this study based on semi-infinite body theory of elastic mechanics to establish a mechanical model along the advancing direction of the working face and derive the stress expression of any point in the affected area of floor mining. According to the theoretical results, effective reinforcement and support schemes are then proposed. FLAC3D numerical simulation analyzes the stress and deformation of the surrounding rock of the floor roadway before and after the reinforcement. The numerical simulation results showed that (1) mining abutment pressure of the overlying working face forms a certain range of stress concentration on the roof and two sides of the roadway and will cause deformation and damage to the floor roadway and (2) overall bearing capacity of the surrounding rock of the roadway is significantly improved, and surface displacement of the floor roadway is reduced by $64 \mathrm{~mm}$ through the reinforcement and support of the floor roadway. On-site monitoring data of the floor roadway in the 11123 working face of Pan'er Mine showed that the maximum displacement of the roadway roof and two sides is controlled at approximately $80 \mathrm{~mm}$, and the surrounding rock deformation of the roadway is appropriately controlled to meet the needs of safe production.
\end{abstract}

\section{Introduction}

Mining conditions of coal seam undermines have become increasingly complex due to the growing demand for coal in recent years. The mining of working faces can easily affect adjacent roadways, including their stability. The roadway is a vital part of mining development and connected to the mining and transportation of coal resources. Therefore, the stability control of the roadway surrounding rock under complex conditions is important for the safe and efficient mining of coal mines [1-8].

Many in-depth studies have been conducted on the failure mechanism and deformation control technology of the surrounding rock of the roadway. Tian et al. [9] used a self-developed bias reaction system to achieve bias loading and investigated the failure mechanism of the surrounding rock of the biased roadway disturbed by mining. Wang et al. [10] used Shandong Hanzhuang Coal Mine Substation as an example, applied on-site monitoring and drilling imaging methods, analyzed the deformation and failure mechanism of the surrounding rock of the roadway, and proposed a segmented bolt grouting reinforcement technology. Yu et al. [11] used FLAC3D numerical calculation and theoretical analysis to reveal the deformation mechanism of the roadway under complex stress conditions. Yu et al. [12] explored a combined support method to improve the stability and safety of the soft rock roadway at Zhongguan Iron Mine in China. Zhang and Liu [13] compared U36 steel support with the concrete-filled steel tube through theoretical calculations and numerical simulations, applied D-CFSTS technology to soft rock roadway support, and predicted its suitability for deep roadway where horizontal 
stress is greater than vertical stress. Wang et al. [14] proposed a U-shaped strip steel roadway support scheme of a horseshoe-shaped arch to address problems, such as close convergence between ribs, large floor deformation, and serious difficulty in roadway support in a fully mechanized caving slab 21203 of Yunmei No. 1 coal mine. Wang [15] provided a conceptual method for the quantitative design of soft rock roadway support through a three-dimensional physical model.

Scholars have successfully conducted many pioneering studies on the failure mechanism of the roadway surrounding rock and its control technology, especially on physical and mechanical properties of the surrounding rock of the roadway and other underground engineering applications. However, studies on the surrounding rock control of roadways under the influence of mining are limited. Engineering conditions of the examined roadway in this study are complex. The engineering measurement results of the project showed that the reinforcement and support scheme meets the requirements of safe production.

\section{Engineering Introduction}

Dongyi group A coal can be found east of the 11123 working face of Pan'er Mine of Huainan Mining Group; the west side of the study area is near the upper roadway of the 12223 working face; the south side is near the 11124 working face floor roadway; and the north is close to the 11223 up groove. This working face is characterized as follows: average buried depth: $-460 \mathrm{~m}$. Overlying coal $3 \#$ and coal $1 \#$ are not mined, and the adjacent 11223 working face is being mined. Main mining coal $3 \#$ has an average thickness and width of $5.5 \mathrm{~m}$ and $160 \mathrm{~m}$, respectively, and a layer of mudstone-intercalated gangue with an average thickness of $0.8 \mathrm{~m}$ is locally developed. The average inclination angle of the coal seam is stable at $10^{\circ}$. The floor roadway under the 11123 working face is used for gas drainage, as shown in Figure 1.

According to the design, the roadway is located on the coal 1\# floor. The surrounding rock of the roadway is mainly sandy mudstone, which exhibits low strength and poor integrity. Under the influence of mining, sandy mudstone is easy to be destroyed, resulting in a large displacement of the roadway surface and serious deformation of the roadway surrounding rock. According to the indoor triaxial compression experiment, mechanical parameters of the surrounding rock under original support conditions are as follows: internal friction angle of the sandy mudstone $\varphi=28^{\circ}$, Poisson's ratio $\mu=0.27$, average compressive strength $\sigma c=15.948 \mathrm{MPa}$, and shear modulus $G=6 \mathrm{GPa}$. The lithology and thickness of each rock layer are shown in Figure 2.

\section{Stress Analysis of the Surrounding Rock in the Floor Roadway of the Working Face}

The floor roadway of the 11123 working face is supported before mining, and the roadway is in a stable state. The original equilibrium state in the floor rock is broken due to the mining of the upper coal seam, and the concentrated stress caused by the mining of the working face transfers to the deep and results in different degrees of floor damage. $\mathrm{Li}$ et al. [16] highlighted that the strong disturbance of deep rock mass easily forms large-scale instability failure and collapse and other strong disturbance dynamic response failures. The stress state of the surrounding rock of the floor roadway affected by mining is analyzed, and the corresponding reinforcement support scheme is proposed to prevent the deformation and instability of the floor roadway in the working face.

3.1. Mining Stress Distribution of the Floor Rock in the Advancing Direction of the Working Face. The original rock stress field of the floor rock mass changes under the influence of mining, and the redistributed stress on the floor results in floor damage after the coal seam is mined. The floor stress distribution depends on transferring the concentrated stress in front of the working face to the lower strata of the coal seam floor $[17,18]$. Combined with the previous analysis of mine pressure and rock formation control theoretical results, a certain range of mining stress increasing and reducing areas form in the coal body and its floor in front of the working face and move forward with the advancement of the working face under the influence of advance abutment pressure of the working face. The distribution state of advance abutment pressure of coal and rock mass along the advancing direction of the working face is divided into three areas, namely, stress reducing, stress increasing, and original rock stress areas [19, 20] (Figure 3).

The stress distribution is expressed in the form of incremental $\triangle \sigma y$ to facilitate the calculation and analysis and simplify the process of theoretical derivation as follows:

$$
\Delta \sigma_{y}=\sigma_{y}-P
$$

where $P$ is the original rock stress.

In Figure 4, I: elastic area, II: plastic area, III: goaf, IV: plastic area, $\mathrm{V}$ : elastic area, $k$ : maximum stress concentration coefficient of solid coal and rear rock mass, and $M$ : position of the floor roadway.

The simplified distribution of stress increment is shown in Figure 4. The coal body in front of the working face is regarded as a semi-infinite homogeneous elastic medium, and the calculation model of stress increment is established. Stress increment distribution characteristics of the coal rock mass and its floor rock mass in front of the working face are obtained in the $x o_{1} y_{1}$ coordinate system by simplifying the advance abutment pressure of the coal and rock mass in front of the working face. The concentration coefficient of the peak stress increase of the surrounding rock in front of the working face is $(\mathrm{k}-1)$ at this time. The representative elemental volume $\mathrm{d} t$ can be taken at the distance $t$ of the coordinate origin $O_{1}$ to superimpose all the stresses caused by each tiny concentrated stress, and vertical and horizontal stress distributions in front of the work surface are obtained to find the stress at any point in the half plane when a half plane is subjected to a vertically distributed load according to the solution of half-plane mechanics in elasticity. The stress distribution function is assumed to be $p(t)=m t+n$ to 


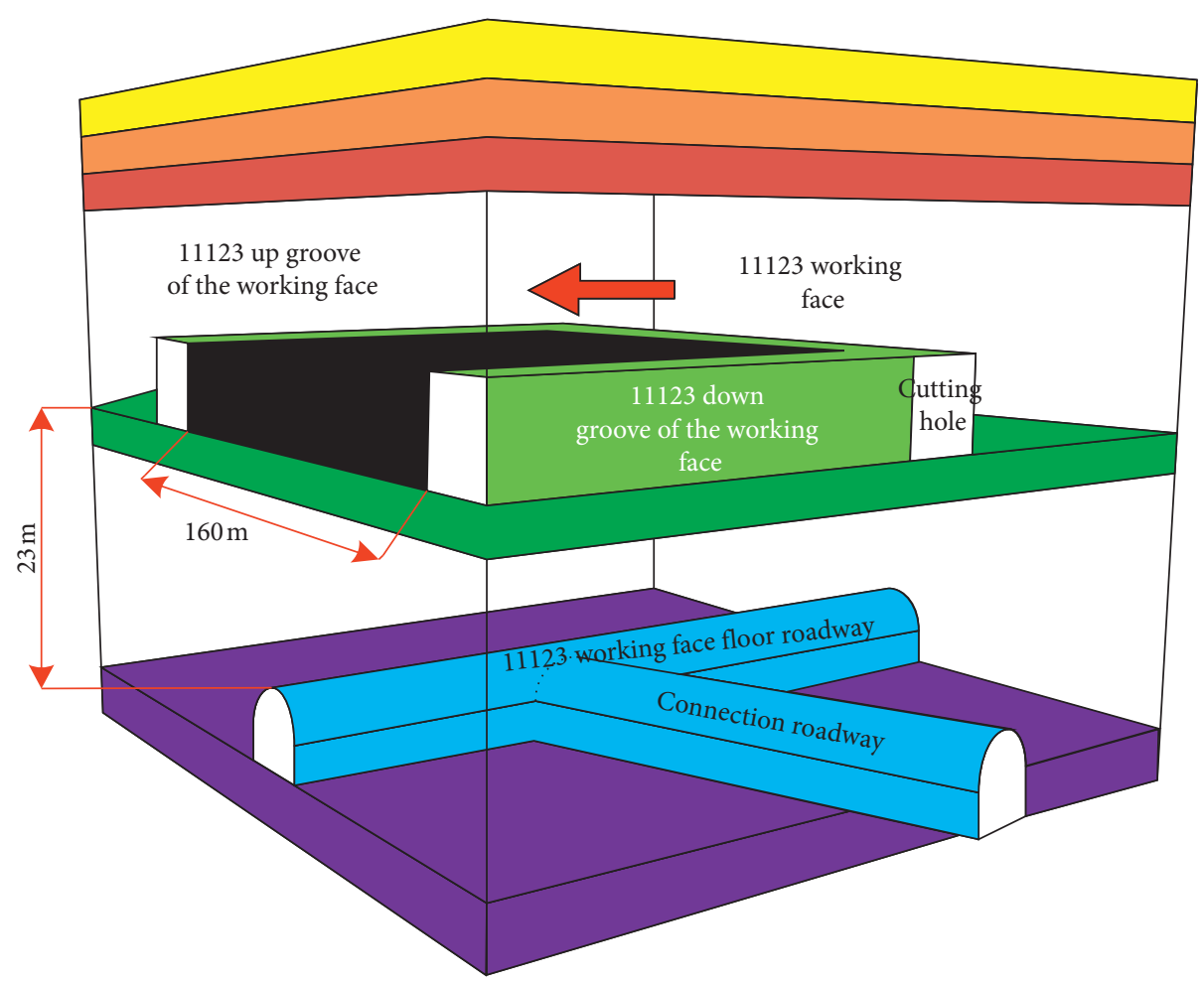

FIGURE 1: Schematic diagram of the roadway layout of the working face floor.

\begin{tabular}{|c|c|}
\hline Lithology & $\begin{array}{c}\text { Thickness } \\
(\mathrm{m})\end{array}$ \\
\hline Sandy shale & 6.0 \\
\hline Mudstone & 1.3 \\
\hline 3 coals & 5.5 \\
\hline Mudstone & 1.5 \\
\hline 1 coal & 3.5 \\
\hline Sandy shale & 3.8 \\
\hline Packsand & 4.2 \\
\hline Mudstone & 9.0 \\
\hline Limestone & 1.2 \\
\hline Packsand & 2.0 \\
\hline Sandy shale & 1.5 \\
\hline Limestone & \\
\hline Coal streak & \\
\hline Mudstone & \\
\hline Limestone & \\
\hline Coal streak & \\
\hline
\end{tabular}

FIGURE 2: Lithology histogram of the 11123 working face. 
facilitate the solution and application of the formula, and the stress in front of the working face can be obtained as follows:

$$
\begin{gathered}
\sigma_{x}=-\frac{y}{\pi}\left[\frac{(m x+n) \arctan (t-x / y)}{y}+m \ln \left((x-t)^{2}+y^{2}\right)\right. \\
\left.+\frac{n(-t+x)+m\left(x^{2}+y^{2}-t x\right)}{(x-t)^{2}+y^{2}}\right]
\end{gathered}
$$$$
\sigma_{y}=-\frac{1}{\pi}\left[\frac{y(t-x)(m x+n)-m y^{3}}{y^{2}+(x-t)^{2}}+(m x+n) \arctan \frac{t-x}{y}\right],
$$

where $m$ and $n$ are linear stress distribution coefficients.

The coordinate axis established in Figure 4 combines equations (2) and (3) to obtain stresses in elastic and plastic zones in front of the working face as follows:

$$
\begin{aligned}
& \left.\sigma_{x_{1}}\right|_{-b} ^{0}=-\frac{y}{\pi}\left[\left(\frac{\left(m_{1} x+n_{1}\right) \arctan (-x / y)}{y}+m_{1} \ln \left(x^{2}+y^{2}\right)+\frac{n_{1} x+m_{1}\left(x^{2}+y^{2}\right)}{x^{2}+y^{2}}\right)\right. \\
& \left.-\left(\left(m_{1} x+n_{1}\right) \arctan \frac{b+x}{y}+m_{1} \ln \left[(x+b)^{2}+y^{2}\right]+\frac{n_{1}(x+b)+m_{1}\left(x^{2}+y^{2}+b x\right)}{(x+b)^{2}+y^{2}}\right)\right] \\
& \left.\sigma_{x_{2}}\right|_{0} ^{a}=-\frac{y}{\pi}\left[\left(\frac{\left(m_{2} x+n_{2}\right) \arctan (a-x / y)}{y}+m_{2} \ln \left[(x-a)^{2}+y^{2}\right]+\frac{n_{2}(x-a)+m_{2}\left(x^{2}+y^{2}-a x\right)}{(x-a)^{2}+y^{2}}\right)\right. \\
& \left.-\left(\frac{\left(m_{2} x+n_{2}\right) \arctan (-x / y)}{y}+m_{2} \ln \left[x^{2}+y^{2}\right]+\frac{n_{2} x+m_{2}\left(x^{2}+y^{2}\right)}{x^{2}+y^{2}}\right)\right], \\
& \left.\sigma_{y_{1}}\right|_{-b} ^{0}=-\frac{1}{\pi}\left[\left(\frac{-x y\left(m_{1} x+n_{1}\right)-m_{1} y^{3}}{x^{2}+y^{2}}+\left(m_{1} x+n_{1}\right) \arctan \frac{-x}{y}\right)\right. \\
& \left.-\left(\frac{-y(x+b)\left(m_{1} x+n_{1}\right)-m y^{3}}{y^{2}+(x+b)^{2}}+\left(m_{1} x+n_{1}\right) \arctan \frac{-b-x}{y}\right)\right], \\
& \left.\sigma_{y_{2}}\right|_{0} ^{a}=-\frac{1}{\pi}\left[\left(\frac{y(a-x)\left(m_{2} x+n_{2}\right)-m_{2} y^{3}}{y^{2}+(x-a)^{2}}+\left(m_{2} x+n_{2}\right) \arctan \frac{a-x}{y}\right)\right. \\
& \left.-\left(\frac{-x y\left(m_{2} x+n_{2}\right)-m_{2} y^{3}}{x^{2}+y^{2}}+\left(m_{2} x+n_{2}\right) \arctan \frac{-x}{b}\right)\right] \text {, }
\end{aligned}
$$

where $\sigma x_{1}$ and $\sigma y_{1}$ are horizontal and vertical stresses in section I, respectively; $\sigma y_{1}$ and $\sigma y_{2}$ are horizontal and vertical stresses in section II, respectively; $a$ is the length of the elastic zone; $b$ is the length of the plastic zone; $m_{1}$ and $n_{1}$ are the stress distribution coefficients of the elastic zone; and $m_{2}$ and $n_{2}$ are the stress distribution coefficients of the plastic zone.

The stress increment calculation model is established in the xoy coordinate system by taking the goaf of the working face as a semi-infinite homogeneous elastic medium. Stress increment distribution characteristics of the floor rock of the goaf are obtained by simplifying the pressure of the goaf, as shown in Figure 4 . The representative elemental volume $\mathrm{d} t$ can be obtained at the distance $t$ of the coordinate origin $O$, and the stress distribution of the goaf is expressed as follows:

$$
\left\{\begin{array}{l}
\sigma_{x}=-\frac{2 q}{\pi} \int_{0}^{x} \frac{y^{*}\left(x^{*}-t\right)^{2} \mathrm{~d} t}{\left[y^{*^{2}}+\left(x^{*}-t\right)^{2}\right]^{2}} \\
\sigma_{y}=-\frac{2 q}{\pi} \int_{0}^{x} \frac{y^{*^{2}} \mathrm{~d} t}{\left[y^{*^{2}}+\left(x^{*^{2}}-t\right)^{2}\right]^{2}}
\end{array}\right.
$$




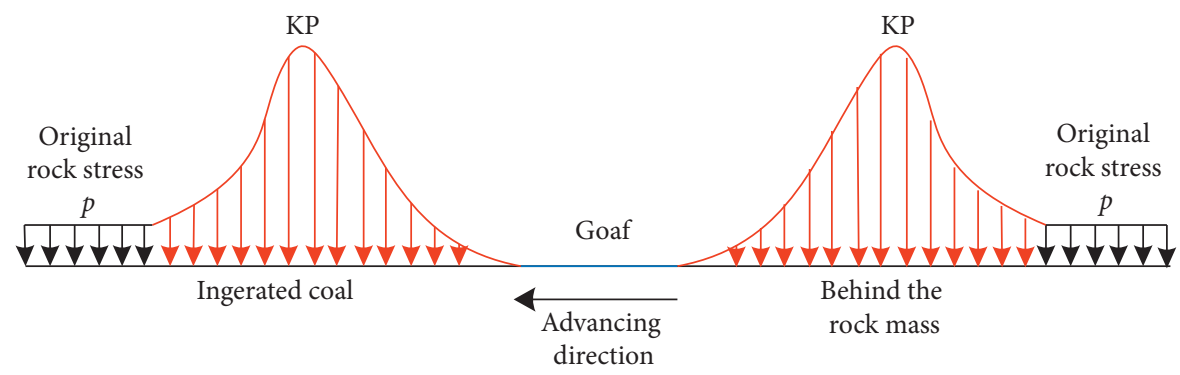

FIgURE 3: Distribution of mining stress.

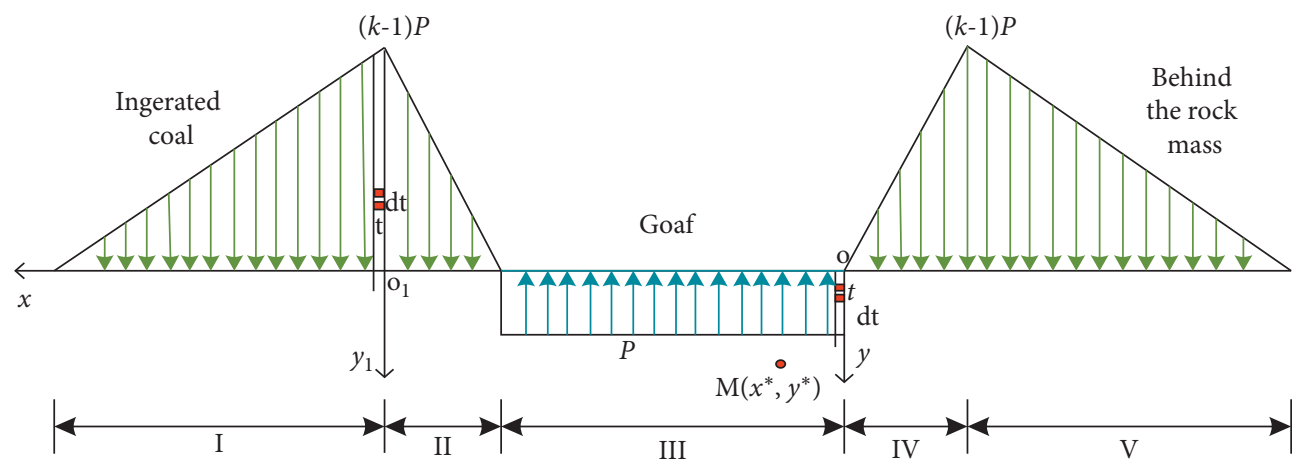

FIgURE 4: Diagram of stress increment distribution.

Vertical and horizontal stresses of the floor roadway at $M$ under the working face are expressed as follows:

$$
\begin{aligned}
& \sigma_{x 3}=-\frac{q}{\pi}\left[\arctan \frac{x^{*}}{y^{*}}-\arctan \frac{x^{*}-x}{y^{*}}+\frac{y^{*} x^{*}}{y^{*^{2}} x^{*^{2}}}+\frac{y^{*}\left(x^{*}-x\right)}{y^{*^{2}}+\left(x^{*}-x\right)^{2}}\right], \\
& \sigma_{y 3}=-\frac{q}{\pi}\left[\arctan \frac{x^{*}}{y^{*}}-\arctan \frac{x^{*}-x}{y^{*}}+\frac{y^{*} x}{y^{*^{2}}+x^{*^{2}}}-\frac{y^{*}\left(x^{*}-x\right)}{y^{*^{2}}+\left(x^{*}-x\right)^{2}}\right] \text {, }
\end{aligned}
$$

where $x^{*}$ and $y^{*}$ are coordinates of floor roadway $M$ and $X$ is the advancing distance of the working face.

According to the spatial layout relationship between the floor roadway and the upper stope of the 11123 working face, the disturbance of the working face advancing on the stress environment around the floor roadway can be divided into three parts, namely, linear concentrated load behind the working face, uniformly distributed load in the goaf, and linear concentrated load in front of the working face, as shown in Figure 4. The mechanical model in front of the working face can be unified into the xoy coordinate system via coordinate translation transformation of the stress increment calculation model of $x o_{1} y_{1}$ in front of the working face. Therefore, horizontal and vertical stresses at $M$ of the floor roadway are obtained as follows:

$$
\left\{\begin{array}{l}
P_{M x}=\sigma_{x 1}^{\prime}+\sigma_{x 2}^{\prime}+\sigma_{x 3}+\sigma_{x 4}+\sigma_{M x} \\
P_{M y}=\sigma_{y 1}^{\prime}+\sigma_{y 2}^{\prime}+\sigma_{y 3}+\sigma_{y 4}+\sigma_{M y}
\end{array}\right.
$$

where $\sigma_{x 1}{ }^{\prime}, \sigma_{x 2}{ }^{\prime}, \sigma_{y 1}{ }^{\prime}$, and $\sigma_{y 2}{ }^{\prime}$ are stress distributions of concentrated stress in front of the working face at the $m$ point under the xoy coordinate system; $\sigma_{x 3}$ and $\sigma_{y 3}$ are distributions of goaf stress to the floor roadway; $\sigma_{x 4}$ and $\sigma_{y 4}$ are concentrated forces produced by the rock mass behind the working face on the floor roadway; and $\sigma_{M y}$ and $\sigma_{M x}$ are initial stresses at the roadway $M$.

3.2. Mechanical State Analysis of the Surrounding Rock of the Floor Roadway in the Working Face under Mining Influence. The failure depth of the roadway surrounding rock under the nonuniform mining stress environment is analyzed according to the Rubinnet equation. The distribution range $s$ of the plastic zone of the roadway surrounding rock is estimated while considering the nonuniform stress condition. The radius and displacement of the plastic zone of floor roadway undermining influence are obtained according to the Rubinnet formula as follows [21]: 


$$
S=R_{0}\left[\frac{\left((1+\lambda) P_{M y}+2\left(\sigma_{c} /\left(K_{p}-1\right)\right)\right)}{\left(K_{p}+1\right)\left(p_{i}+\sigma_{c} /\left(K_{p}-1\right)\right)}\right]^{\left(1 /\left(K_{p}-1\right)\right)}+\frac{21-\lambda P_{M y} \cos (2 \theta) R_{0}}{\left((1+\lambda) P_{M y}+2\left(\sigma_{c} /\left(K_{p}-1\right)\right)\right)\left(K_{P}-1\right)}\left[\frac{\left(1+\lambda p_{M y}+2\left(\sigma_{c} /\left(K_{P}-1\right)\right)\right)}{\left(K_{p}+1\right)\left(p_{i}+\left(\sigma_{c} /\left(K_{P}-1\right)\right)\right)}\right]^{\left(1 /\left(K_{p}-1\right)\right)}
$$

where $\theta$ is the angle between $X$-axis; $P_{M y}$ is the vertical stress load caused by mining; $\lambda$ is the lateral stress coefficient under the mining stress environment, $\lambda=P_{M x} / P_{M y} ; R_{0}$ is the equivalent roadway radius; $\sigma_{\mathrm{c}}$ is the uniaxial compressive strength of the rock; $P_{\mathrm{i}}$ is the support resistance; $\varphi$ is the angle of internal friction; and $K_{p}=(1+\sin (\phi)) /(1-\sin (\phi))$.

According to $\mathrm{Bu}[22]$, the displacement equation of the surrounding rock in the floor roadway is obtained as follows:

$$
u=\frac{S^{2}}{4 G r}\left\{(\lambda+1) p+\frac{2 \sigma_{c}}{K_{p}-1}\left(\frac{K_{p}+1}{K_{p}-1}\right)+2(\lambda-1) p(1-\mu) \frac{\cos (2 \theta)}{1-2(f(\theta) / S)}-\left(\frac{S}{r}\right)^{2}\left[(\lambda-1) p(1-2 \mu) \frac{3 \cos (2 \theta)}{1-4(f(\theta) / S)}\right]\right\}
$$

where $G$ is the shear modulus of the surrounding rock and $\mu$ is Poisson's ratio.

\subsection{Stress Distribution of the Floor Roadway under the In-} fluence of Mining. By taking the floor roadway under the 11123 working face as the engineering background, the floor roadway is located at the position of $y *=23 \mathrm{~m}$ below the stope, and the roadway at $x *=30 \mathrm{~m}$ is used in the surrounding rock stress analysis. At this time, additional stresses $\sigma_{x 4}$ and $\sigma_{y 4}$ generated by the concentrated stress behind the working face can be treated as a constant and calculated at $\sigma_{x 4}=1.95 \mathrm{MPa}$ and $\sigma_{y 4}=0.95 \mathrm{MPa}$, respectively. Vertical and horizontal stress change curves of the roadway as the working face advances are shown in Figure 5.

Figure 5 shows that the vertical stress of the roadway surrounding rock at $x *=30 \mathrm{~m}$ increases first and then gradually decreases as the working face advances. The vertical stress of the roadway reaches its maximum value of $20.5 \mathrm{MPa}$ when the working face advances by $21 \mathrm{~m}$. Compared with the initial vertical stress, it increased by $6.5 \mathrm{MPa}$. The horizontal stress of the roadway showed a general decreasing trend by demonstrating a state of decreasing, increasing, and then decreasing during the advancement of the working face. The theoretical results showed that the surrounding rock stress of the roadway is significantly affected by the mining, and the change of surrounding rock stress will lead to the breaking of the original equilibrium state of the roadway and then the development of the plastic zone and reduction of the surrounding rock strength.

3.4. Analysis of Roadway Surface Displacement. Figure 6 shows that the displacement of the surrounding rock of the roadway has a negative correlation with the support resistance. The high support resistance reduces the displacement of the surrounding rock of the roadway. The displacement of the surrounding rock of the roadway is sensitive to the support resistance when the support resistance is small, but sensitivity reduces with the gradual increase of the support resistance.

\section{Roadway Surrounding Rock Control Technology}

4.1. Range Analysis of the Plastic Zone. Cohesive force, internal friction angle, and support resistance were $C=3.0 \mathrm{MPa}, \varphi=27^{\circ}$, and $P_{\mathrm{i}}=0.2 \mathrm{MPa}$, respectively, under the original support. Analysis of the plastic fracture zone $s$ of the surrounding rock of the roadway at the position $x *=30 \mathrm{~m}$ changes with the mining depth of the working face range. The equivalent circumscribed radius of the roadway section of the bottom floor is assumed to be equal to $R_{0}=2.4 \mathrm{~m}$.

As shown in Figure $7(a)$, specific mechanical state changes with the continuous advancement of mining on the overlying working face of the roadway are expressed as follows:

(1) The vertical stress environment of the roadway surrounding rock in the area of advance abutment pressure of working face increasing leads to the redistribution of roadway stress and the plastic failure range of the roadway surrounding rock showing an "oval" distribution when the overlying working face advances by $20 \mathrm{~m}$.

(2) The vertical stress condition of rock mass around the roadway is in the decreasing area and basically coincides with the horizontal stress when the overlying working face advances by $40 \mathrm{~m}$. The stress redistribution of the roadway caused by the deep extension of the coal wall in front of the working face leads to the plastic failure range of the surrounding rock in the form of a "vertical ellipse."

(3) The vertical stress of surrounding rock mass decreases rapidly, and the horizontal stress is higher than the vertical stress when the overlying working face advances by $60 \mathrm{~m}$. At this time, the stress redistribution of the roadway leads to the plastic failure range of the surrounding rock in the form of a "vertical ellipse." 


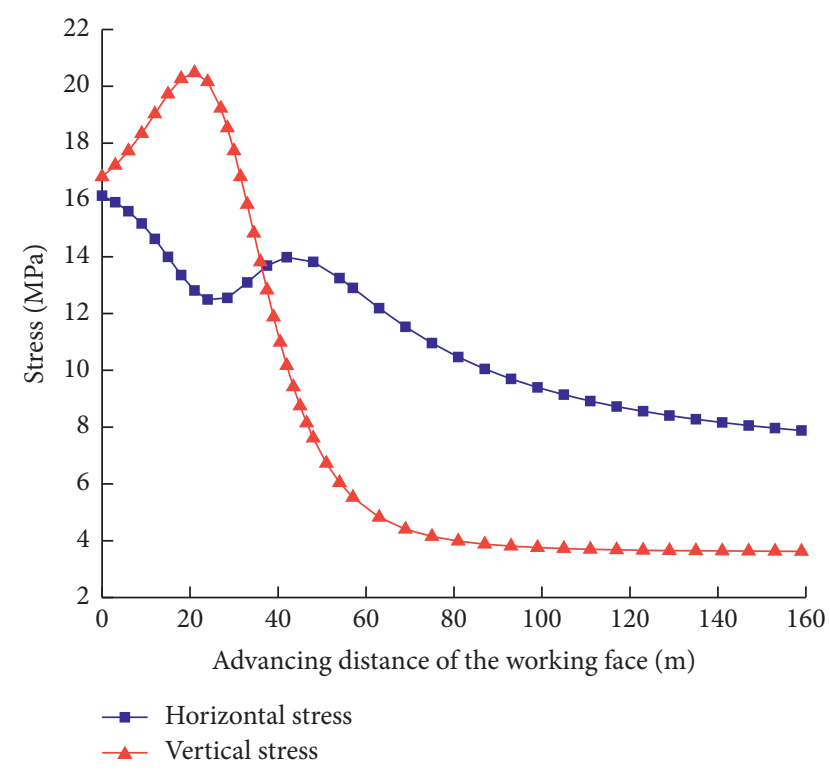

Figure 5: Schematic diagram of stress change.

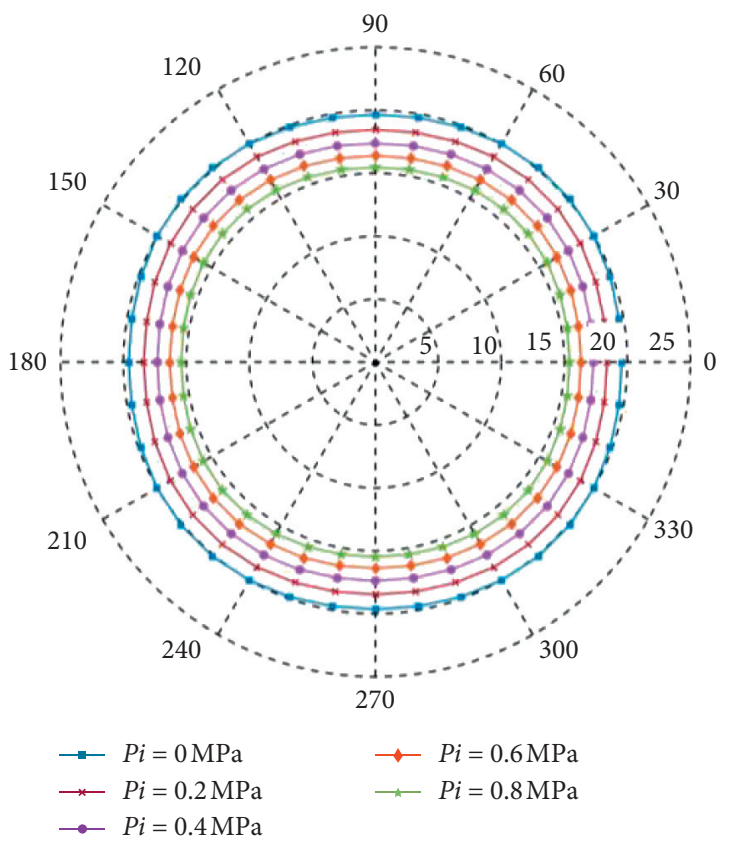

FIGURE 6: The influence of different support resistances on the displacement of the surrounding rock in the roadway.

(4) The stress environment of surrounding rock mass is the weakest stage when the overlying working face advances by $120 \mathrm{~m}$. However, the damage range of the surrounding rock is in an irrecoverable weakening stage due to the influence of advance abutment pressure of the working face.

Figure 7(b) illustrates that the radius of the plastic zone of the roadway with the support is smaller than the radius without the support, and the stability of the surrounding rock of the roadway is evidently strengthened by the support after the analysis of surrounding rock parameters.
Figure 8 demonstrates that the radius of the roadway plastic zone is negatively related to the internal friction angle and cohesion. High cohesion reduces the radius of the roadway plastic failure zone when the internal friction angle is the same, and the large angle of internal friction reduces the radius of the roadway plastic failure zone under the same cohesion. The grouting reinforcement method can generally increase the internal friction angle and cohesion and reduce the plastic zone range in the surrounding rock. The radius of the plastic failure zone of the roadway has a negative correlation with the support resistance. High support resistance reduces the radius of the plastic failure zone of the roadway. The radius of the plastic zone around the roadway is sensitive to the support resistance when the support resistance is small, but sensitivity reduces with the gradual increase of support resistance.

4.2. Reinforcement and Support Scheme. According to the parameter analysis, grouting reinforcement increases the integrity of the surrounding rock and improves the internal friction angle and cohesion of the surrounding rock. Highdensity bolt and cable support increase the integrity of the roadway surrounding rock and the support resistance. Anchor-grouting support method with the grouting anchor cable as the core is adopted, that is, the anchor cable support is adopted first, followed by the use of shotcrete, and the anchor-grouting reinforcement is used after a certain delay. As shown in Figure 9, the grouting anchor cable specification is $\Phi 22 \times 6300 \mathrm{~mm}$ of steel-stranded wire, with a row spacing of $1900 \times 2000 \mathrm{~mm}$. Two anchor cables at corresponding positions in two adjacent rows are connected by \#12 or \#10 channel steel, and one section has five grouting anchor cables and then grouting reinforcement for the surrounding rock of the roadway.. Each hole is equipped with three rolls of Z2355 medium-speed resin medicine, and the pullout resistance is designed at $10 t$. The grouting reinforcement is designed with a $50 \mathrm{~mm}$-thick spray layer to prevent the mortar from running out.

\section{Numerical Simulation Analysis}

5.1. Model Building. The numerical simulation software FLAC3D is adopted according to the relevant geological conditions of the 11123 working face in Pan'er Coal Mine, and a three-dimensional numerical model of the working face and floor roadway is established to reflect the stress and deformation law of the floor roadway directly during mining. The design model is $300 \mathrm{~m}$ (length) $\times 300 \mathrm{~m}$ (width) $\times 390 \mathrm{~m}$ (height) to prevent the possible boundary effect in the simulation process and ensure the accuracy of the calculation. The vertical stress applied to the upper boundary of the model is $5.0 \mathrm{MPa}$, and the horizontal stress varying with the depth is applied to both sides of the model because the buried depth of the 11123 working face is approximately $470 \mathrm{~m}$. The vertical displacement of the lower surface of the model is fixed, and the lateral displacement is constrained by the left and right boundaries. The grid around the floor roadway is refined, and the regional grid far 


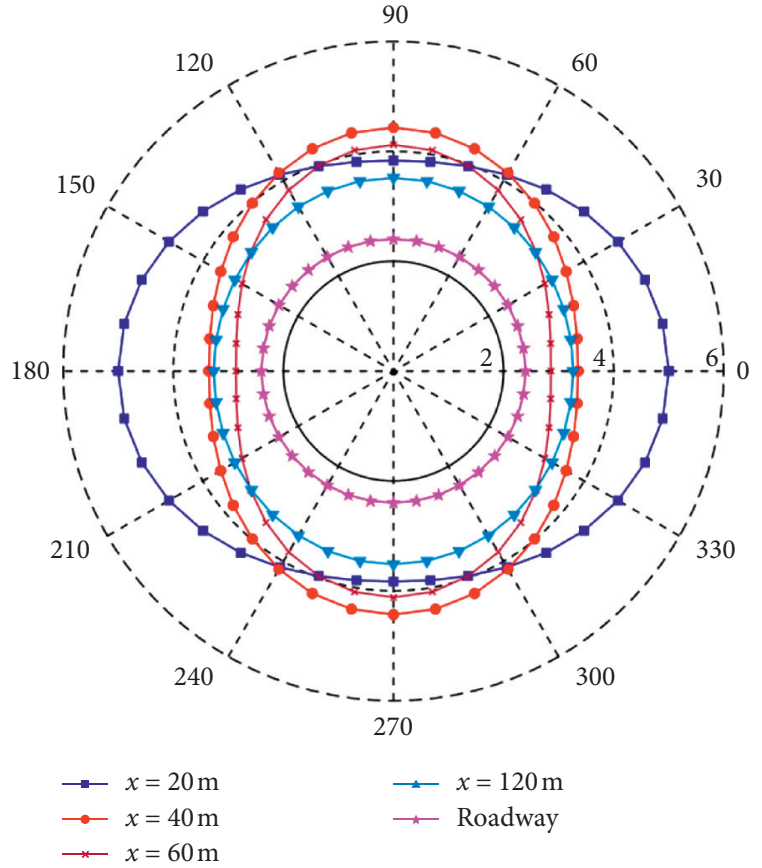

(a)

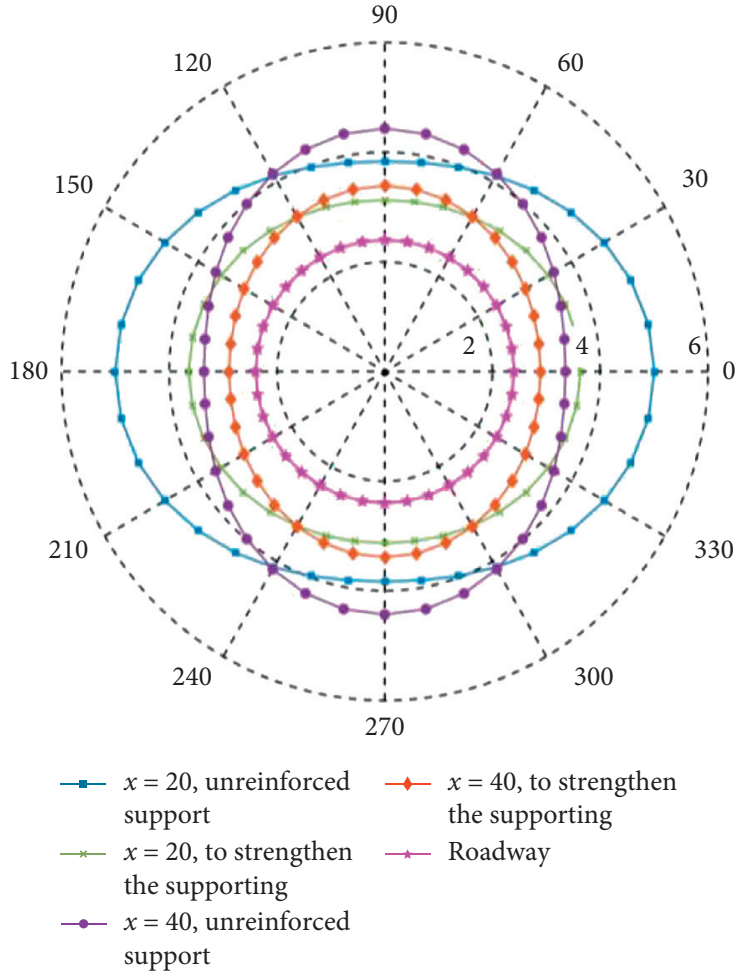

(b)

FIGURE 7: Failure radius diagram of the plastic zone of the surrounding rock of the roadway: (a) plastic zone radius of the surrounding rock with different advancing distances and (b) plastic zone radius of the surrounding rock before and after grouting reinforcement.

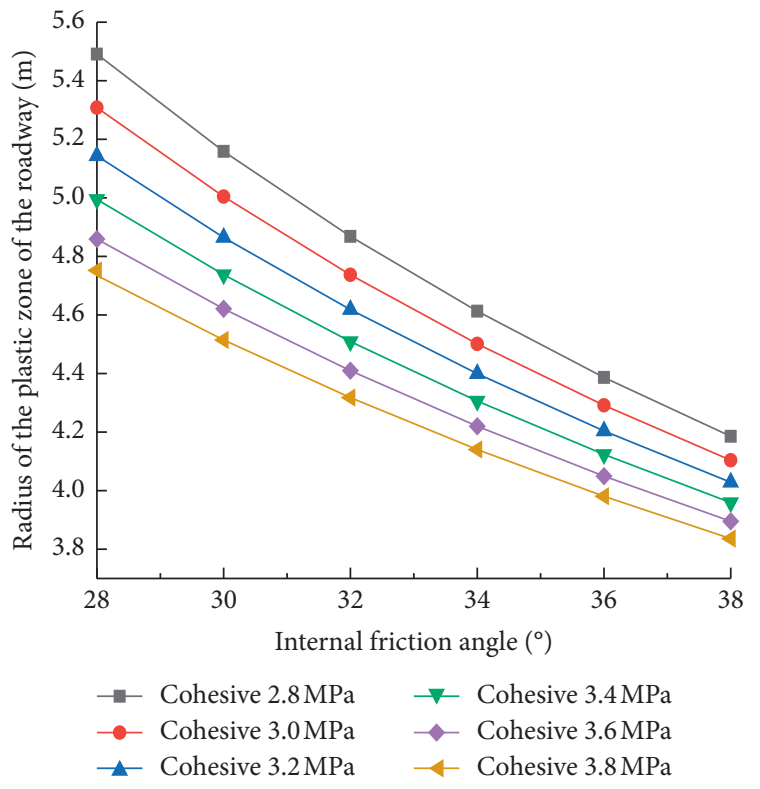

(a)

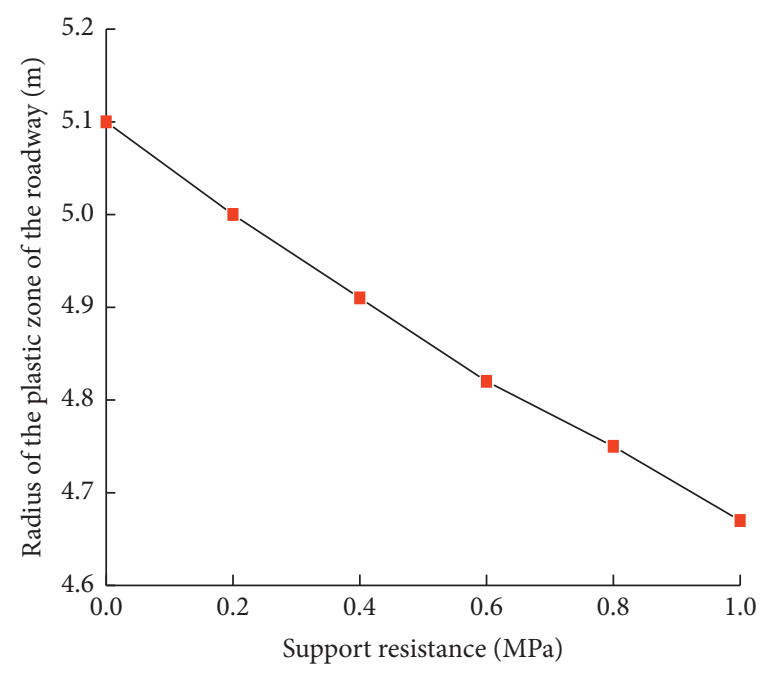

(b)

FiguRE 8: Influence of surrounding rock parameters on radius of the plastic zone of the roadway.

from the floor roadway is appropriately sparse to improve the calculation efficiency because the stress and displacement around the floor roadway are the critical areas of the simulation calculation, as shown in Figure 10. The cross section of the floor roadway is a $1.2 \mathrm{~m}$-high straight wall with a $2.4 \mathrm{~m}$-high semicircle arch $(4.8 \mathrm{~m}$ (width)). Considering the nonlinear large deformation characteristics of the surrounding rock of the floor roadway, the Mohr-Coulomb 


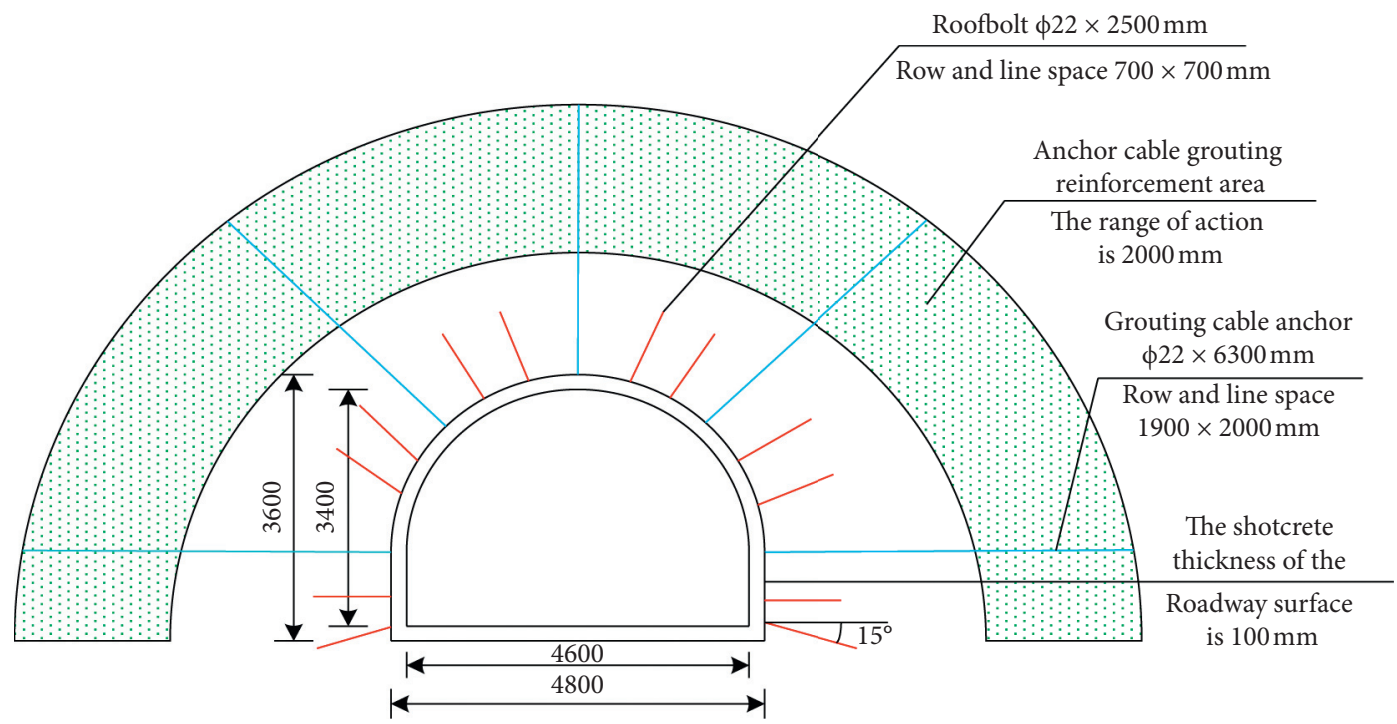

Figure 9: Schematic diagram of reinforcement and support + original support.

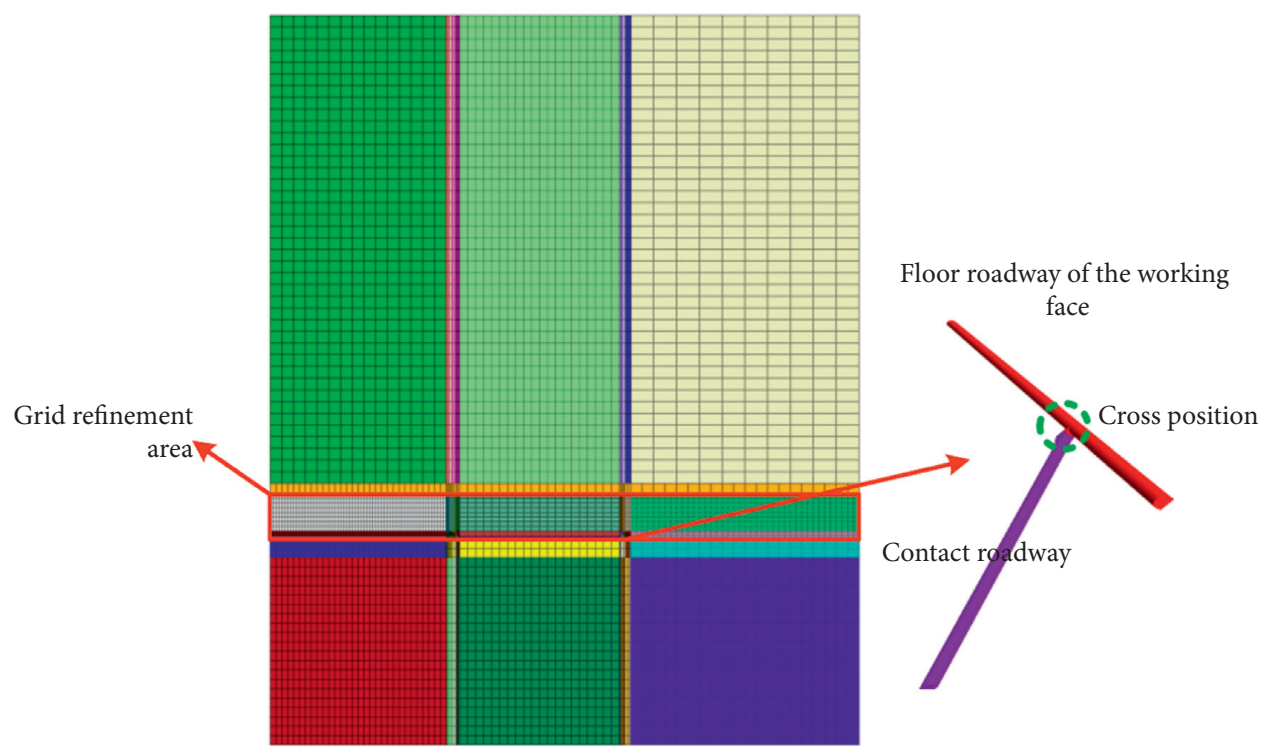

Figure 10: FLAC3D numerical analysis model.

strength criterion is selected to assess the failure of surrounding rock mass in the calculation of numerical simulation. Parameters of each rock stratum are listed in Table 1.

\subsection{Surrounding Rock Evolution Characteristics of the} Roadway before Reinforcement. The roadway position $x^{*}=30 \mathrm{~m}$ on the floor of the working face is sliced to explore the evolution characteristics of the roadway surrounding rock during the advancing process of the working face and observe the stress and displacement of the roadway surface.

As shown in Figure 11, the mining of the working face has a strong disturbance to the surrounding rock of the roadway, and the surrounding rock of the roadway produces a large range of stress concentration areas. In the initial stage of mining, the stress concentration of the roadway roof is the most obvious. With the advance of the working face, the influence of mining on the roadway is weakened. At this time, the stress concentration value of the roadway roof is obviously reduced, and the two sides of the roadway are weakened with the increase of advancing distance of the working face. The stress concentration of the roof and two sides is approximately 19.59 and $13.50 \mathrm{MPa}$ when the mining advancement of the 11123 working face is $12 \mathrm{~m}$. The surrounding rock of the roadway is affected by the stress concentration, the surrounding rock of the roadway will produce a large area of broken area, and at the same time, it will increase the scope of the plastic zone of the surrounding rock, which easily produces large-scale deformation and instability. The stress release of the roof and two sides in the goaf stress release area reaches $0.85 \mathrm{MPa}$ with the continuous advancement of the 11123 working face. The bearing 
TABLE 1: Physical and mechanical parameters of each rock stratum.

\begin{tabular}{|c|c|c|c|c|c|c|}
\hline Lithology & $\begin{array}{l}\text { Bulk density } \\
\left(\mathrm{kg} \cdot \mathrm{m}^{-3}\right)\end{array}$ & $\begin{array}{l}\text { Bulk modulus } \\
\qquad(\mathrm{GPa})\end{array}$ & $\begin{array}{l}\text { Shear modulus } \\
(\mathrm{GPa})\end{array}$ & $\begin{array}{c}\text { Internal friction } \\
\text { angle }\left(^{\circ}\right)\end{array}$ & $\begin{array}{c}\text { Cohesion } \\
\text { (MPa) }\end{array}$ & $\begin{array}{c}\text { Strength of tensile } \\
(\mathrm{MPa})\end{array}$ \\
\hline Sandy shale & 2532 & 11 & 6 & 28 & 2.1 & 2 \\
\hline Mudstone & 2465 & 4.6 & 3.8 & 32 & 1.2 & 0.87 \\
\hline Packsand & 2620 & 20.4 & 11.9 & 36 & 12 & 2.4 \\
\hline Limestone & 2746 & 24.6 & 13.6 & 34 & 2.5 & 4.5 \\
\hline Coal & 1385 & 2.3 & 1.5 & 28 & 1.2 & 0.38 \\
\hline
\end{tabular}

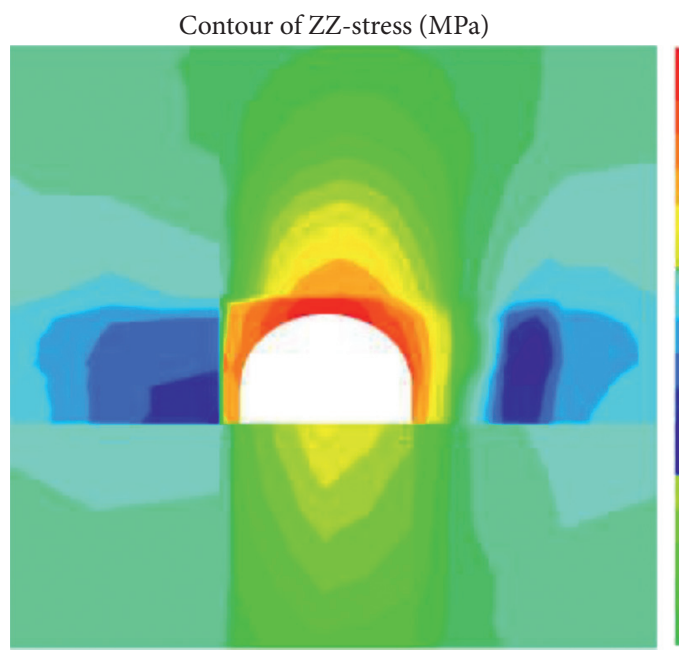

(a)

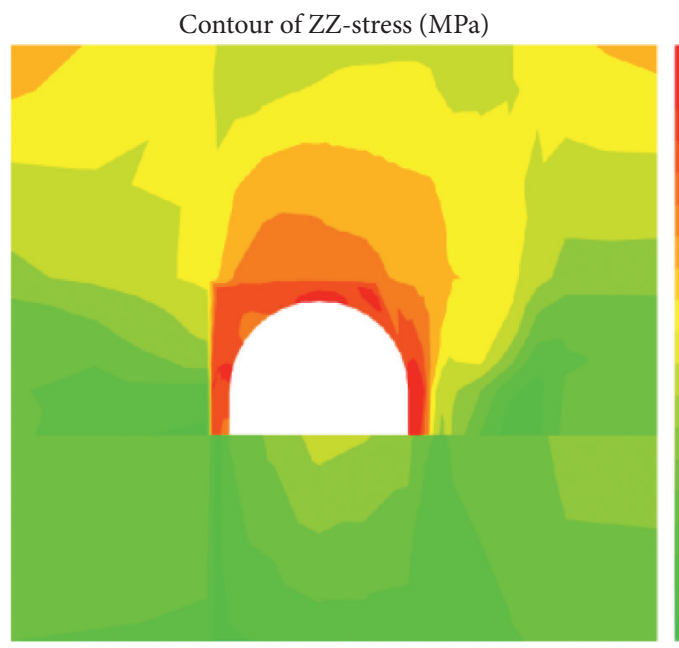

(c)

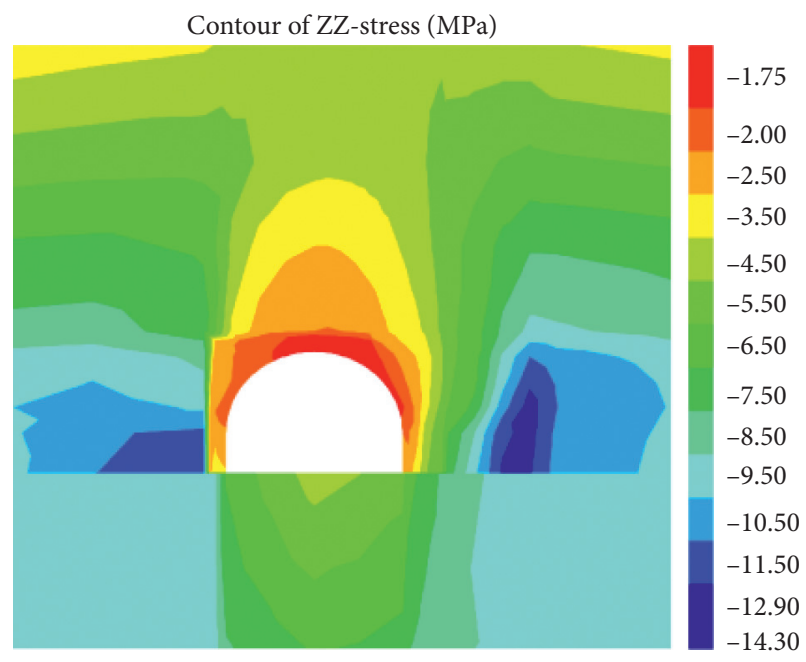

(b)

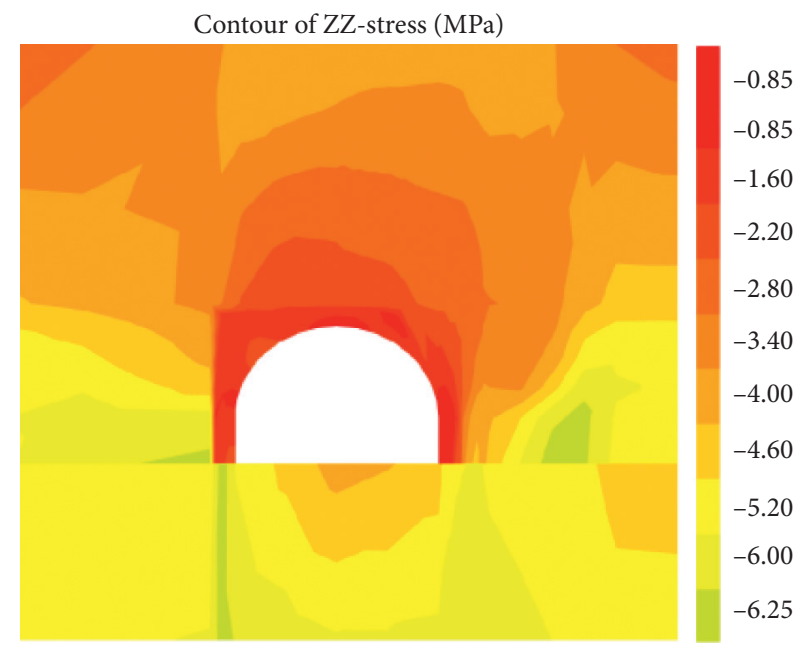

(d)

FIGURE 11: Stress change diagram of the surrounding rock before reinforcement: (a) working face advancing $12 \mathrm{~m}$, (b) working face advancing $36 \mathrm{~m}$, (c) working face advancing $60 \mathrm{~m}$, and (d) working face advancing $84 \mathrm{~m}$.

capacity of the surrounding rock reduces, and the surface deformation of the surrounding rock increases due to the large stress release value of the surrounding rock of the roadway.

As shown in Figure 12, the deformation of the roadway surrounding rock increases with the increase of advancing distance of the working face, and the deformation of the roadway roof is the most serious. With the advance of the working face, the influence of mining on the surrounding rock of the roadway is deepened, and the disturbance produced by working face advancing continuously acts on the roadway. The roadway surface will produce a 


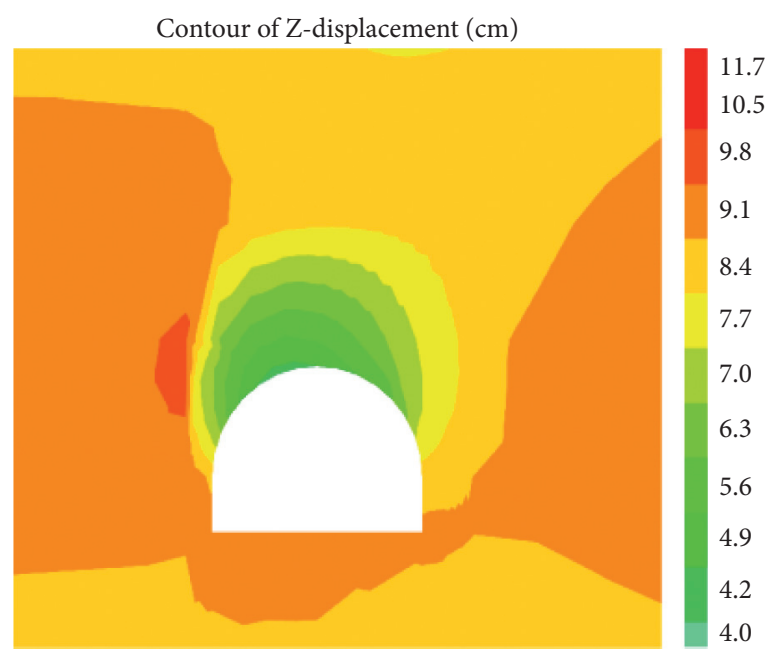

(a)

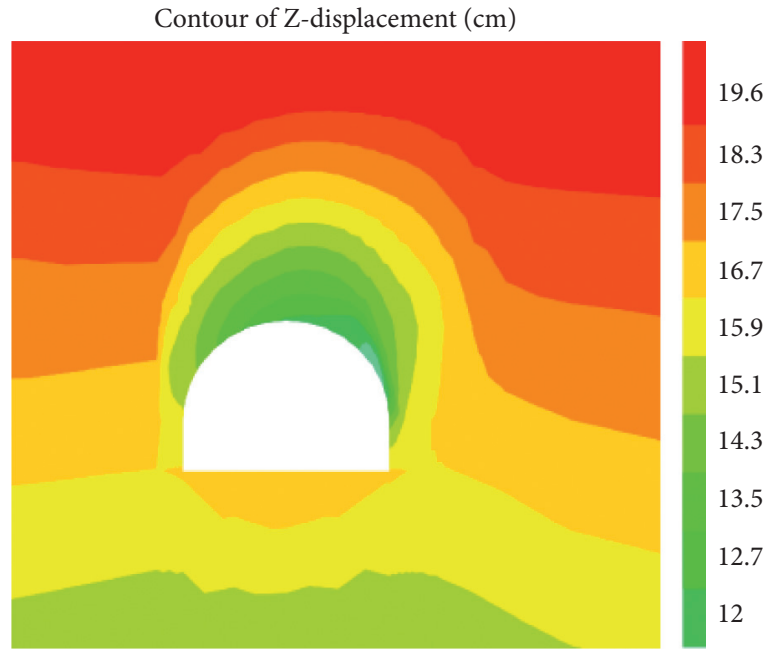

(c)

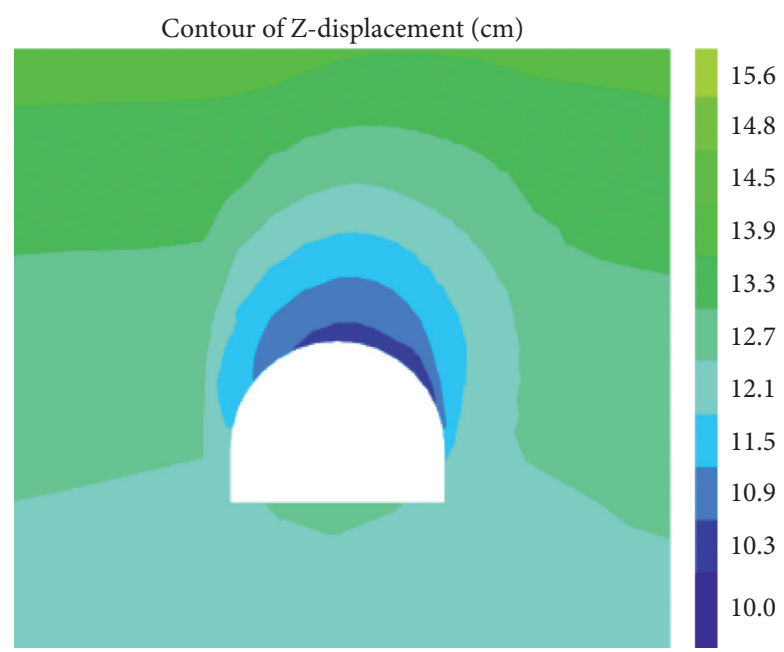

(b)

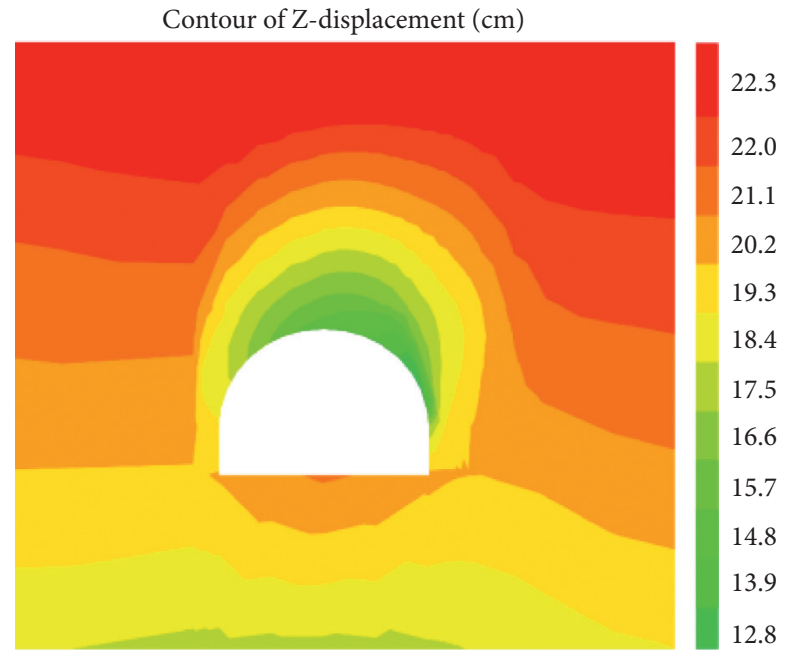

(d)

FIGURE 12: Diagram of displacement change of the surrounding rock of the roadway before reinforcement: (a) working face advancing $12 \mathrm{~m}$, (b) working face advancing $36 \mathrm{~m}$, (c) working face advancing $60 \mathrm{~m}$, and (d) working face advancing $84 \mathrm{~m}$.

displacement of $4.0 \mathrm{~cm}$ under the influence of stress concentration when the working face is pushed forward by $12 \mathrm{~m}$. The floor roadway of the working face is in the goaf stress release area with the continuous advancement of the 11123 working face. At this time, the influence of mining stress on the environment gradually weakens due to the reduction in the bearing capacity of the surrounding rock caused by the stress release and the impact of mining of the surrounding rock mass of the roadway caused by the advancement of the working face in the early stage. The damage range of the surrounding rock of the roadway is in an irreversible weakening stage, and the maximum displacement of the surrounding rock surface can reach $12.8 \mathrm{~cm}$.

5.3. Evolution Characteristics of the Surrounding Rock of the Roadway after Reinforcement. As shown in Figure 13, the stress concentration area and the peak value of the roadway surrounding rock show an obvious weakening trend. With the advance of the working face, the influence of mining on the roadway is weakened. After reinforcement and support, the bearing structure of the surrounding rock makes the stress of the surrounding rock of the roadway tend to a stable state, weakening the influence of advancing of the working face on the surrounding rock of the roadway, and the support of the roadway effectively slows down the deformation trend of the surrounding rock of the roadway. The peak stress concentration of the roof and two sides decreased to 18.20 and $13.30 \mathrm{MPa}$, respectively, and the range of stress concentration significantly reduced. The stress release value of the roof and two sides increased from $0.85 \mathrm{MPa}$ to 2.65 $\mathrm{MPa}$, which avoided the phenomenon of decreasing bearing capacity of the surrounding rock and increasing surface deformation of the surrounding rock due to excessive stress release.

As shown in Figure 14, the integrity and bearing capacity of the roadway surrounding rock increase after reinforcement and support. The overall displacement of the roadway 


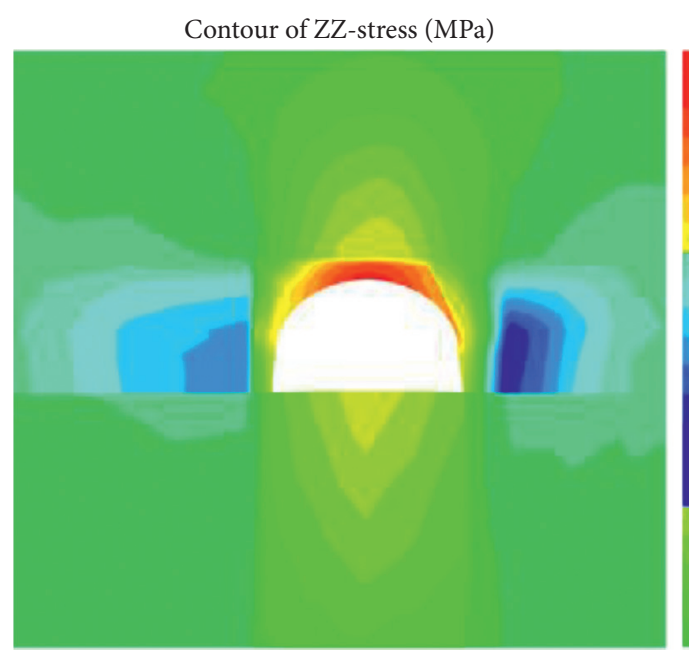

(a)

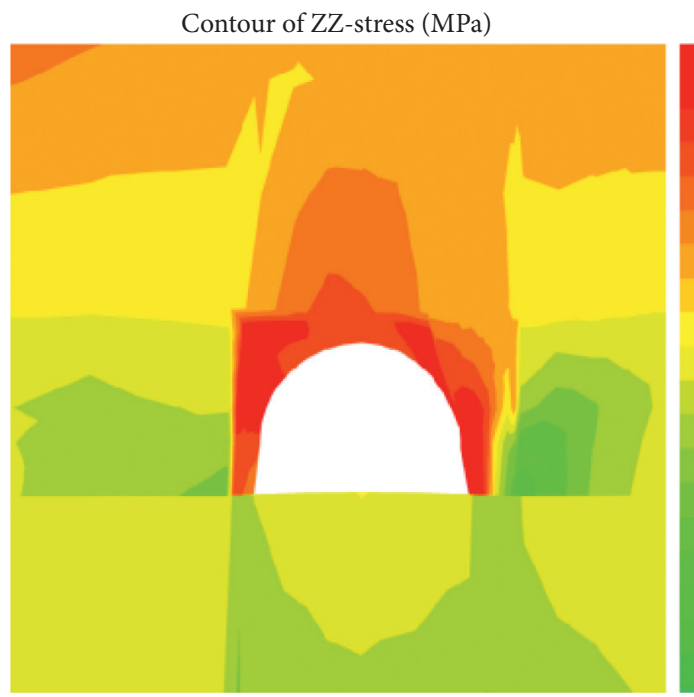

(c)

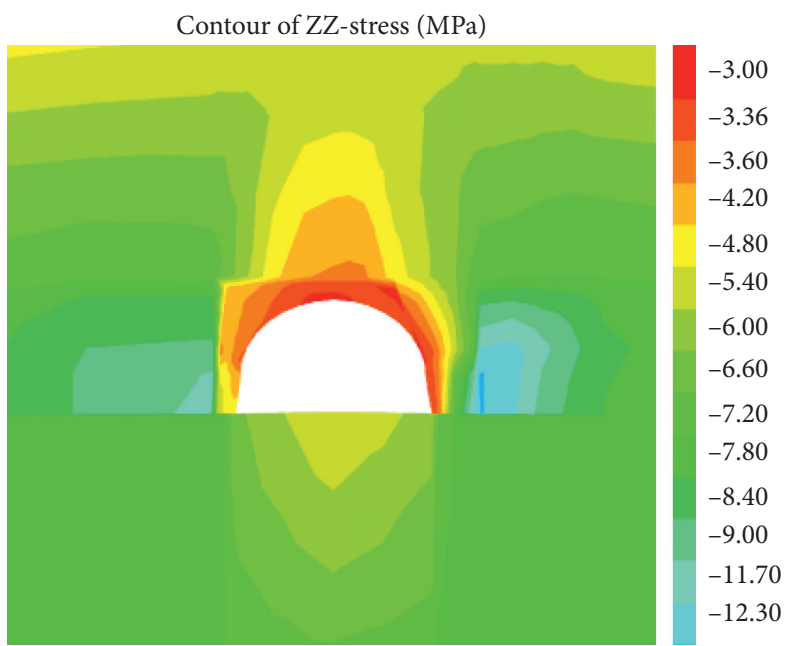

(b)

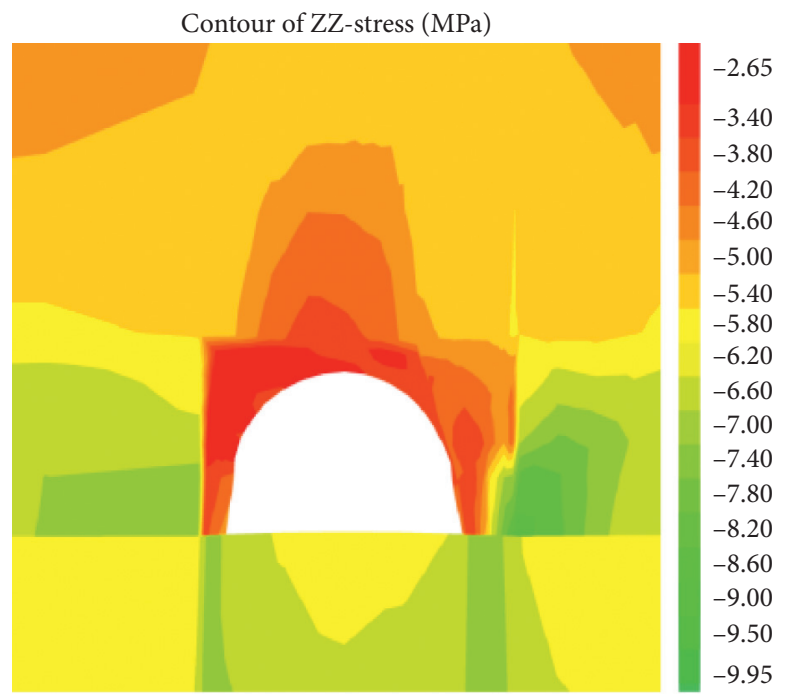

(d)

FIGURE 13: Stress change diagram of the surrounding rock after reinforcement: (a) working face advancing $12 \mathrm{~m}$, (b) working face advancing $36 \mathrm{~m}$, (c) working face advancing $60 \mathrm{~m}$, and (d) working face advancing $84 \mathrm{~m}$.

surrounding rock decreases, the influence of mining on surrounding rock deformation is weakened, and the deformation of the surrounding rock tends to be stable in the latter stage, and the deformation of the surrounding rock is in a controllable state. Stress release leads to the reduction of surrounding rock bearing capacity, and the surrounding rock of the roadway is affected by mining due to the advancement of the working face in the early stage, and the influence of these two factors on the surface displacement of the roadway surrounding rock decreases. The surface displacement of the surrounding rock of the roadway is reduced from $12.8 \mathrm{~cm}$ to $6.4 \mathrm{~cm}$, and the reinforcement control effect is acceptable.

\section{Engineering Application}

The reinforcement scheme is proposed to prevent instability and damage in the floor roadway of the 11123 working face in Pan'er Mine caused by the mining stress. The effect of the reinforcement and support plan is evaluated through field observation during the advancing process of the working face. Displacement monitoring points are designed on the roof and two sides of the roadway to monitor the deformation of the roadway roof and two sides, as shown in Figure 15.

Figure 15 shows that the displacement of the surrounding rock on the roof and two sides is approximately 8 


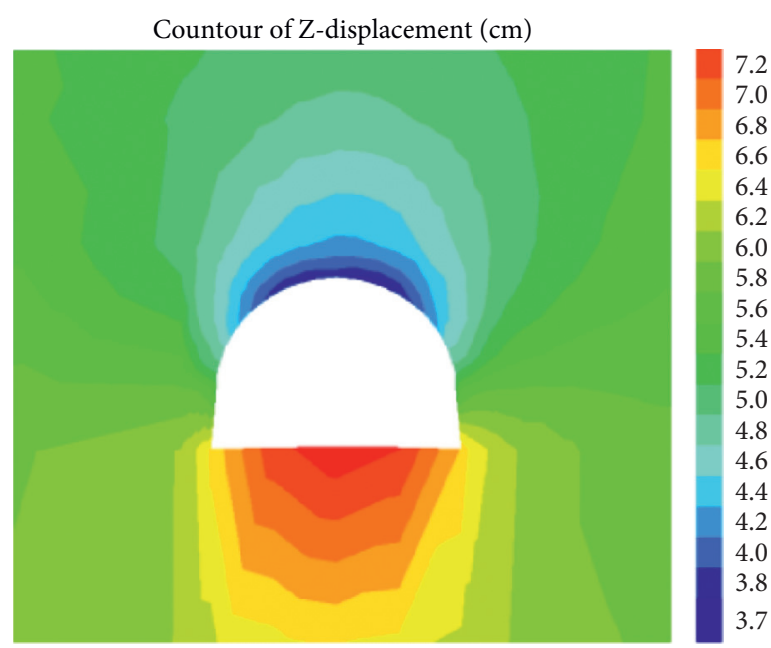

(a)

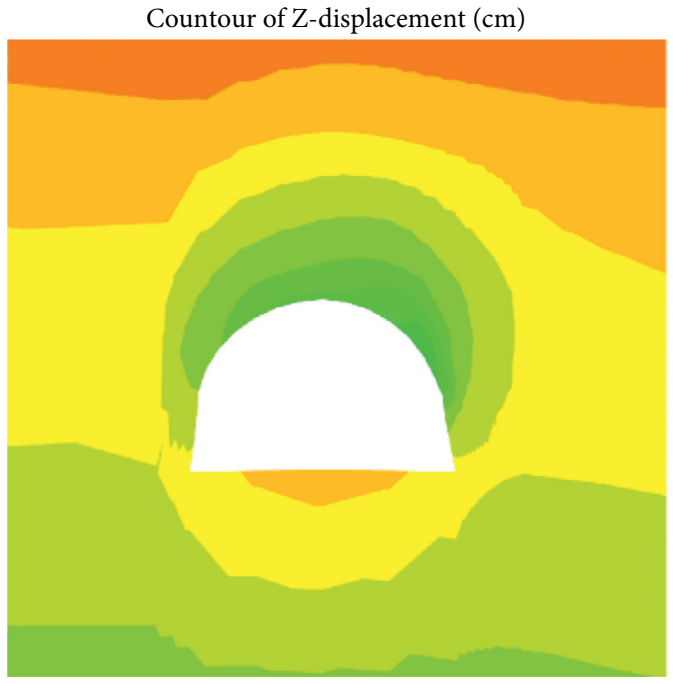

(c)

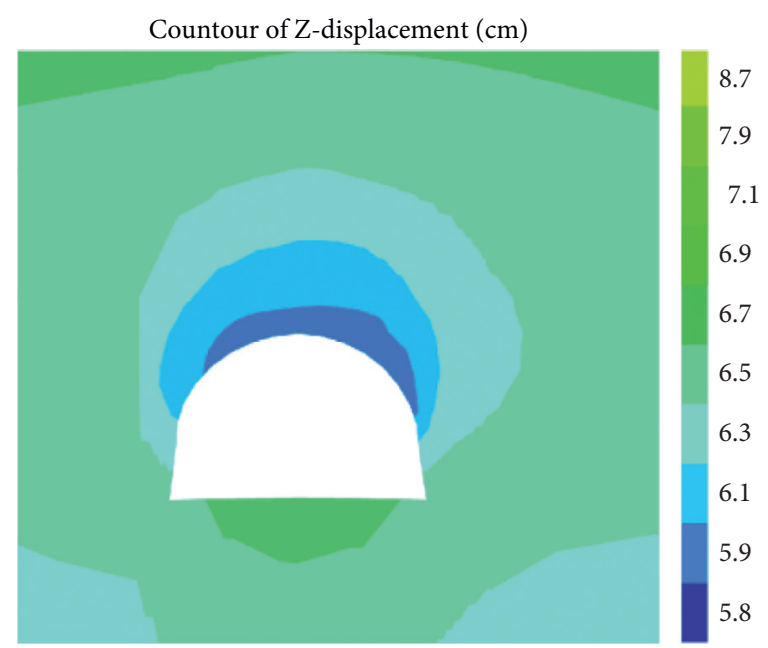

(b)

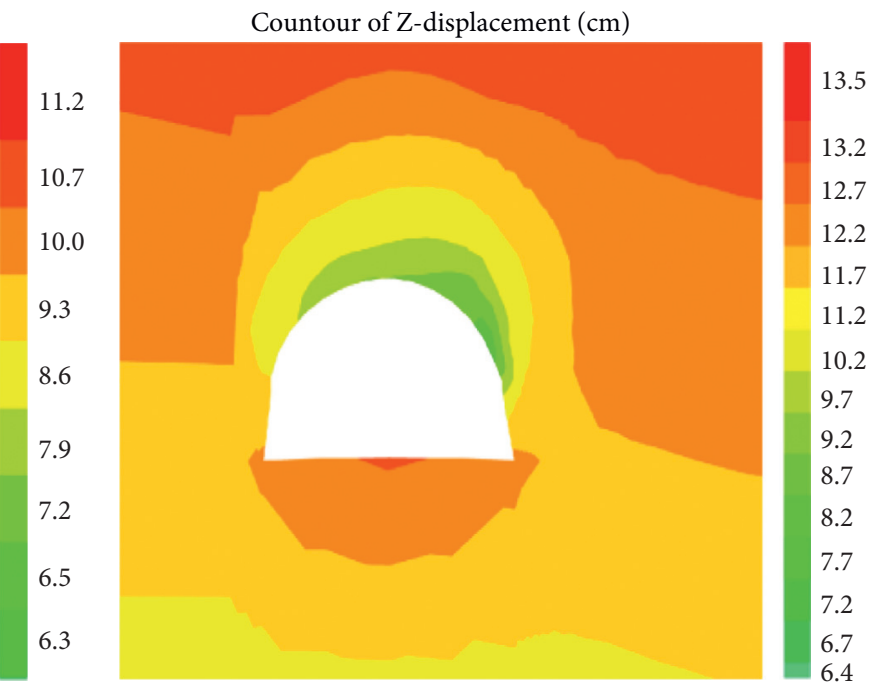

(d)

FIGURE 14: Diagram of displacement change of the surrounding rock of the roadway before reinforcement: (a) working face advancing $12 \mathrm{~m}$, (b) working face advancing $36 \mathrm{~m}$, (c) working face advancing $60 \mathrm{~m}$, and (d) working face advancing $84 \mathrm{~m}$.

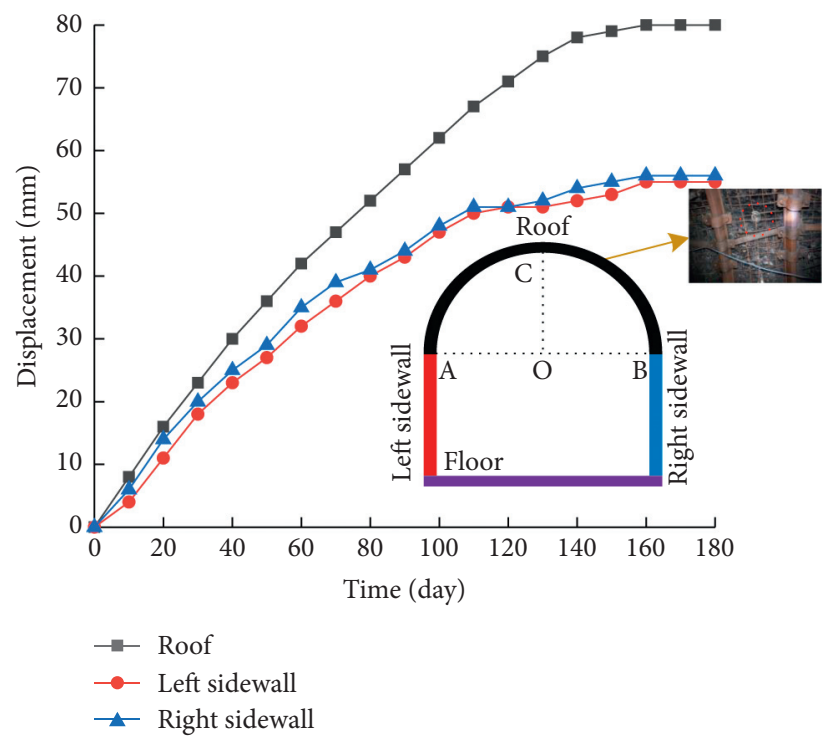

FIGURE 15: Roadway surface displacement monitoring. 
and $5.6 \mathrm{~cm}$, respectively, and the phenomenon of anchor bolt and cable breaking away from anchor is absent. The field monitoring data showed that the reinforcement scheme improves the bearing capacity and stability of the roadway roof and two sides, and the surrounding rock deformation is appropriately controlled.

\section{Conclusion}

(1) The abutment pressure produced by the mining of the overlying working face forms the stress concentration on the surface of the floor roadway, which can easily cause a large-range displacement of the surrounding rock on the roadway surface. The reinforcement and support should be carried out on the floor roadway to avoid instability and damage of the floor roadway.

(2) The change of stress and displacement of the roadway surrounding rock before and after reinforcement is assessed via numerical simulation. The results showed that the surrounding rock demonstrated a higher peak stress concentration before reinforcement than after reinforcement, and the roadway surrounding rock clearly exhibited less surface displacement after reinforcement than before reinforcement. The reinforcement scheme demonstrates satisfactory control effect.

(3) The reinforcement and support scheme based on the mechanical analysis of the instability and failure of the floor roadway of the working face is proposed to increase the integrity and bearing capacity of the surrounding rock of the roadway. The engineering measurement results showed that the displacement of the roadway roof and two sides of the surrounding rock is only around 8 and $5.6 \mathrm{~cm}$, respectively, with evident surrounding rock control effect. The reinforcement and support scheme meets the requirements of mine safety production.

\section{Data Availability}

The nature of the data is the field observation data, numerical simulation data, and the theoretical calculation data. The data used to support the findings of this study are available from the corresponding author upon request.

\section{Conflicts of Interest}

The authors declare that they have no conflicts of interest.

\section{Acknowledgments}

The authors gratefully acknowledge the financial support of the National Natural Science Foundation of China (grant no. 51674007).

\section{References}

[1] R. Peng, Z. H. Ouyang, Q. F. Zhao, and J. M. Zhu, "Studies on support techniques for roadway bearing structure features under different geo-pressures," Arabian Journal of Geosciences, vol. 2020, Article ID s12517-020-06157-1, 13 pages, 2020.

[2] J. C. Chang, D. Li, T. F. Xie, W. B. Shi, and K. He, "Deformation and failure characteristics and control technology of roadway surrounding rock in deep coal mines," Geofluids, vol. 2020, Article ID 8834347, 15 pages, 2020.

[3] J. C. Chang, K. He, Z. Q. Yin, W. F. Li, S. H. Li, and D. D. Peng, "Study on the instability characteristics and bolt support in deep mining roadways based on the surrounding rock stability index: example of pansan coal mine," Advances in Civil Engineering, vol. 2020, Article ID 8855335, 16 pages, 2020.

[4] Q. Y. Xu, Y. M. Li, J. Lu, and L. Zhang, "The use of surrounding rock loosening circle theory combined with elasticplastic mechanics calculation method and depth learning in roadway support," PLoS One, vol. 2020, 14 pages, 2020.

[5] S.-Z. Luo and W.-Z. Liang, "Optimization of roadway support schemes with likelihood-based MABAC method," Applied Soft Computing, vol. 80, no. 2019, pp. 80-92, 2019.

[6] Z. F. Du, "In-situ stress measurement at deep position and optimization of roadway support structure parameters in underground mines," Earth and Environmental Science, vol. 446, p. 8, Article ID 052091, 2020.

[7] Y. Tai, G. Lu, H. Xia, J. Liu, and Y. Zhang, "Control of the chamber in extra-thick coal seam based on fracture characteristics of coal rock and mass," Advances in Civil Engineering, vol. 2020, no. 2020, 13 pages, 2020.

[8] Y. T. Sun, G. C. Li, and J. C. Zhang, "Investigation on jet grouting support strategy for controlling time-dependent deformation in the roadway," Energy Science \& Engineering, vol. 8, no. 2020, pp. 2151-2158, 2020.

[9] M. L. Tian, J. L. Han, Q. B. Meng, and C. Ma, "Physical model experiment of surrounding rock failure mechanism for the roadway under deviatoric pressure form mining disturbance," KSCE Journal of Civil Engineering, vol. 24, no. 4, pp. 1102$1115,2020$.

[10] H. Wang, C. Jiang, P. Q. Zheng, N. Li, and Y. B. Zhan, "Deformation and failure mechanism of surrounding rocks in crossed-roadway and its support strategy," Engineering Failure Analysis, vol. 116, Article ID 104743, 2020.

[11] Y. Yu, J. B. Bai, K. Chen, X. Y. Wang, T. Q. Xiao, and Y. Chen, "Failure mechanism and stability control technology of rock surrounding a roadway in complex stress conditions," Mining Science and Technology (China), vol. 21, no. 2011, pp. 301-306, 2011.

[12] K. P. Yu, F. Y. Ren, P. Ruslan, P. Lin, and Q. G. Meng, "Optimization of combined support in soft-rock roadway," Tunnelling and Underground Space Technology, vol. 103, p. 14, Article ID 103502, 2020.

[13] J. P. Zhang and L. M. Liu, "R\&D and application of curved D-shape concrete-filled steel tube support in roadway support," Geotechnical and Geological Engineering, vol. 36, no. 2018, pp. 551-566, 2018.

[14] H. T. Wang, D. Cheng, Y. J. Wang, T. Li, and N. H. Qu, "Research of mechanical characteristics and roadway support in two-soft and one-hard coal seam," Earth and Environmental Science, vol. 186, p. 7, Article ID 012032, 2018.

[15] C. Wang, "The optimal support intensity for coal mine roadway tunnels in soft rocks," International Journal of Rock 
Mechanics \& Mining Sciences, vol. 37, no. 2000, pp. 11551160, 2000.

[16] X. Li, Q. Yao, J. Man, C. Chen, and L. He, "Development of fractures in soft rock surrounding a roadway and their control," Mining Science and Technology (China), vol. 21, no. 4, pp. 573-579, 2011.

[17] X. F. Guo, Z. Q. Zhao, X. Gao, X. Y. Wu, and N. J. Ma, "Analytical solutions for characteristic radii of circular roadway surrounding rock plastic zone and their application," International Journal of Mining Science and Technology, vol. 29, no. 2019, pp. 263-272, 2019.

[18] L. G. Wang, Y. Wu, and J. Sun, "Three-dimensional numerical simulation on deformation and failure of deep stope floor," Procedia Earth and Planetary Science, vol. 1, no. 2009, pp. 577-584, 2009.

[19] Y. L. Xu, K. R. Pan, and H. Zhang, "Investigation of key techniques on foor roadway support under the impacts of superimposed mining:theoretical analysis and feld study," Environmental Earth Sciences, vol. 78, no. 2019, pp. 84318439, 2019.

[20] Q. S. Huang and J. L. Cheng, "Analytical model of stress field and failure depth in multilayered rock masses of mining floor based on the transfer matrix method," Geotechnical and Geological Engineering, vol. 35, no. 2017, pp. 2781-2788, 2017.

[21] W. X. Zheng, Q. W. Bu, and Y. Q. Hu, "Plastic failure analysis of roadway floor surrounding rocks based on unified strength theory," Advances in Civil Engineering, vol. 2018, p. 10, Article ID 7475698, 2018.

[22] Q. W. Bu, Study of Bolting Support Technology for Mining Gateway with Thick Mudstone Roof in Xinqiao Coal Mine, China, 2014. 